\title{
SURPRISES AT THE SCISSONS CENTRE NEAR SASKATOON
}

TIM HAUGHIAN, 6 Bateman Crescent, Saskatoon, SK S7H 3C2

Species traveling considerable distances beyond their historic ranges may use valley corridors, important areas worthy of increased study as well as protection. Eagle Creek is one such corridor as MAPS volunteers at the Ed and May Scissons Environmental Education Center in the Eagle Creek coulee found out last summer. MAPS (Monitoring Avian Productivity and Survivorship) operates a mist netting program at the Scissons Center situated 56 km NW of Saskatoon, and on July 27, volunteers caught and banded two species north of their usual ranges. One, an adult male Lazuli Bunting, a fair bit north of its expected range, may have simply been passing through as it was caught only once. Multiple captures of another unexpected species, the Yellow-breasted Chat, an impressive, thrush-sized member of the wood-warbler group, indicate breeding at the site (Figure 1).

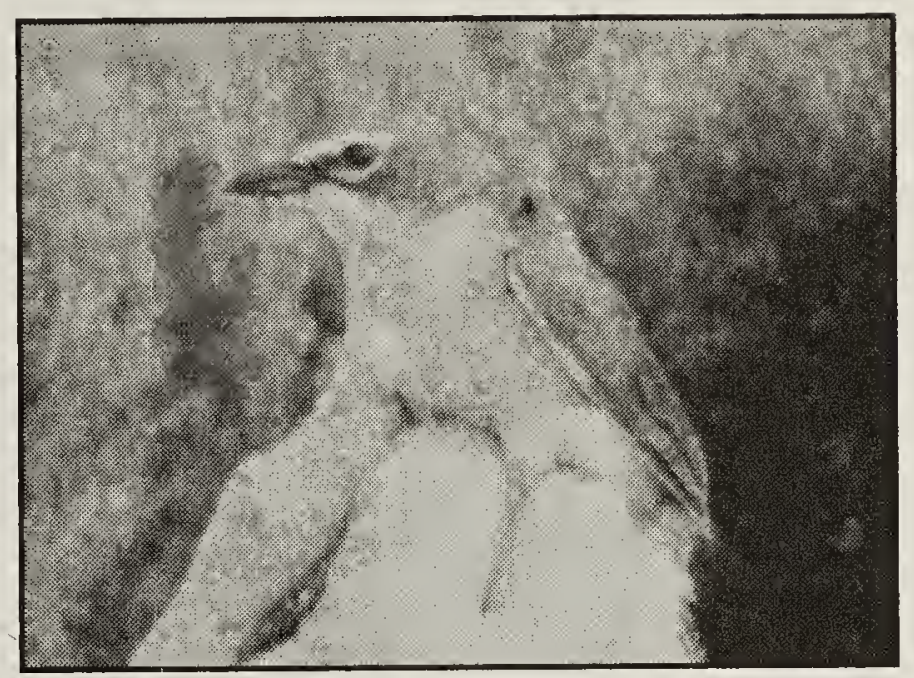

Figure 1. Yellow-breasted Chat at the Scissons Centre, May 2003

Terri Troupe-Logue

The MAPS station at the Scissons Center consists of 10 mist nets arranged in a circle on an 18 hectare plot within a quarter section of native prairie straddling the coulee at Eagle Creek. Volunteers catch and band songbirds during 6-hour morning sessions

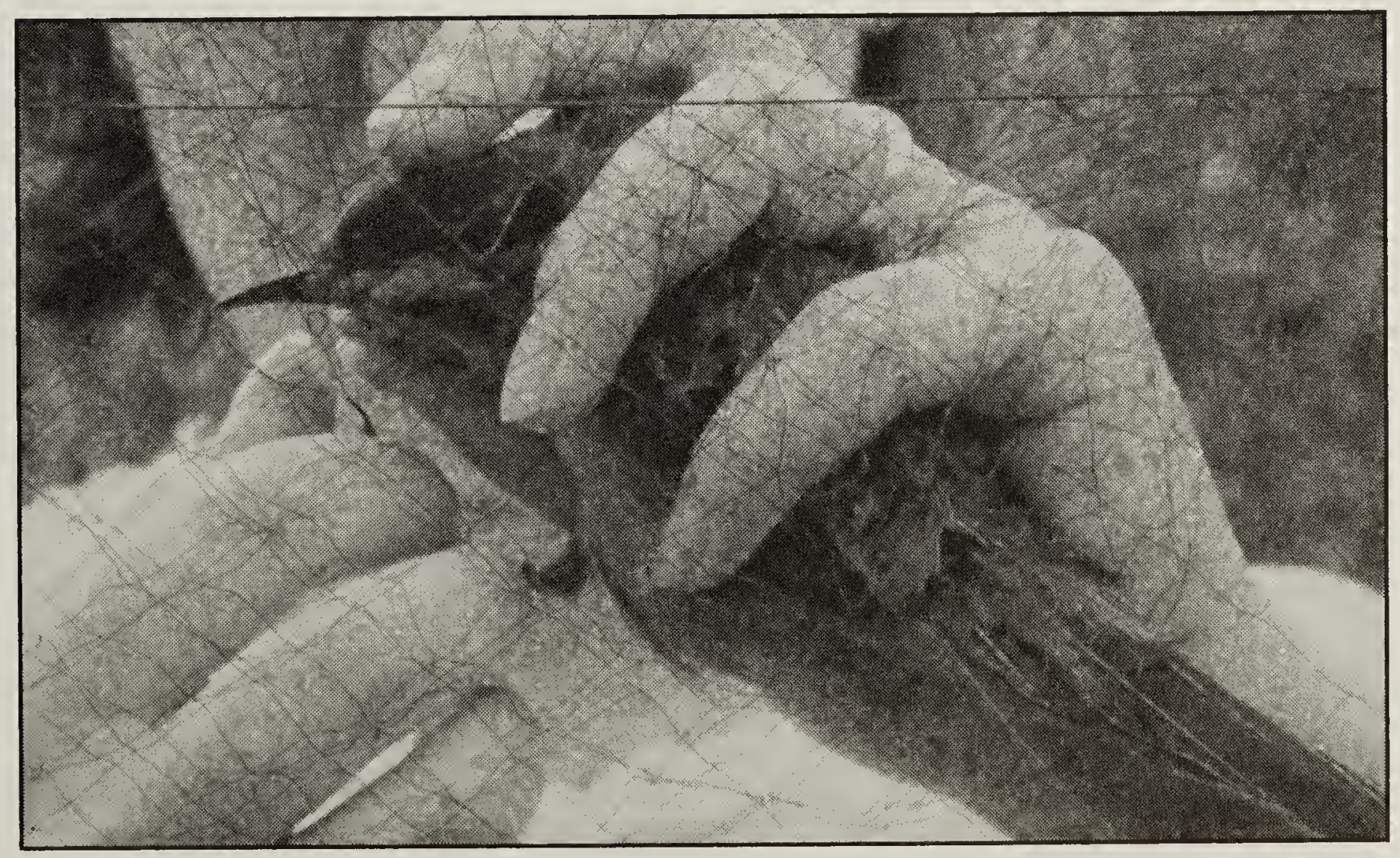


held once in each 10-day stretch throughout the breeding season from June 10 to August 8 (Figures 2 and 3 ).

Four years ago, Rob Wapple, the field biologist who completed the habitat assessment for this MAPS site, suspected that the breeding range of the Yellow-breasted Chat might extend further north than previous records indicated.' He suggested that sampling a creek valley in central Saskatchewan could provide the evidence.

In 2002, Melanie Elliott had a brief glimpse of a Yellow-breasted Chat at the Scissons site. On July 5, in 2003-the station's third year of operation-the first Yellowbreasted Chat was caught, in net \#3. It was an adult male in full breeding condition. Later that morning, in the adjacent net, \#2, we found an adult female, sporting a "full" brood patch, indicating nesting activity. (When she was recaptured in net \#3 on July 20 , her brood patch was ranked as "wrinkled", the next expected stage of brood patch condition.) The locations of the captures provided clues as to nest location and later that day, the male was seen displaying to his mate from atop a thicket directly between the cuts where nets $\# 2$ and \#3 had been placed. A third Yellow-breasted Chat was captured on 27 July in net \#8, about $200 \mathrm{~m}$ south of nets \#2 and \#3. Apparently, the breeding pair of birds were not the only members of their kind on the property! The sex of this new bird was not determined, but molt signs indicated it was an adult. On August $4^{\text {th }}$, the last banding day of the season, as if to complete the saga, a fledgling chat was netted. It can't be said for sure that it was an offspring of the pair banded earlier, but it can be considered evidence of breeding in the Saskatoon area, and more specifically, the northernmost stretch of the Eagle Creek valley.

The MAPS station at the Scissons Environmental Education Center is one of about 500 MAPS stations across the continent and is the only one in Saskatchewan. This international project, managed by the Institute for Bird Populations in Point Reyes, California, enables scientists to monitor songbird populations as a measure of environmental change. To date, Scissons Center volunteers have banded approximately 650 birds belonging to 48 species. Twenty-eight species of birds were captured during the 2003 season. The center is operated by the Saskatoon Catholic Schools Environmental Education Department, with the support of the

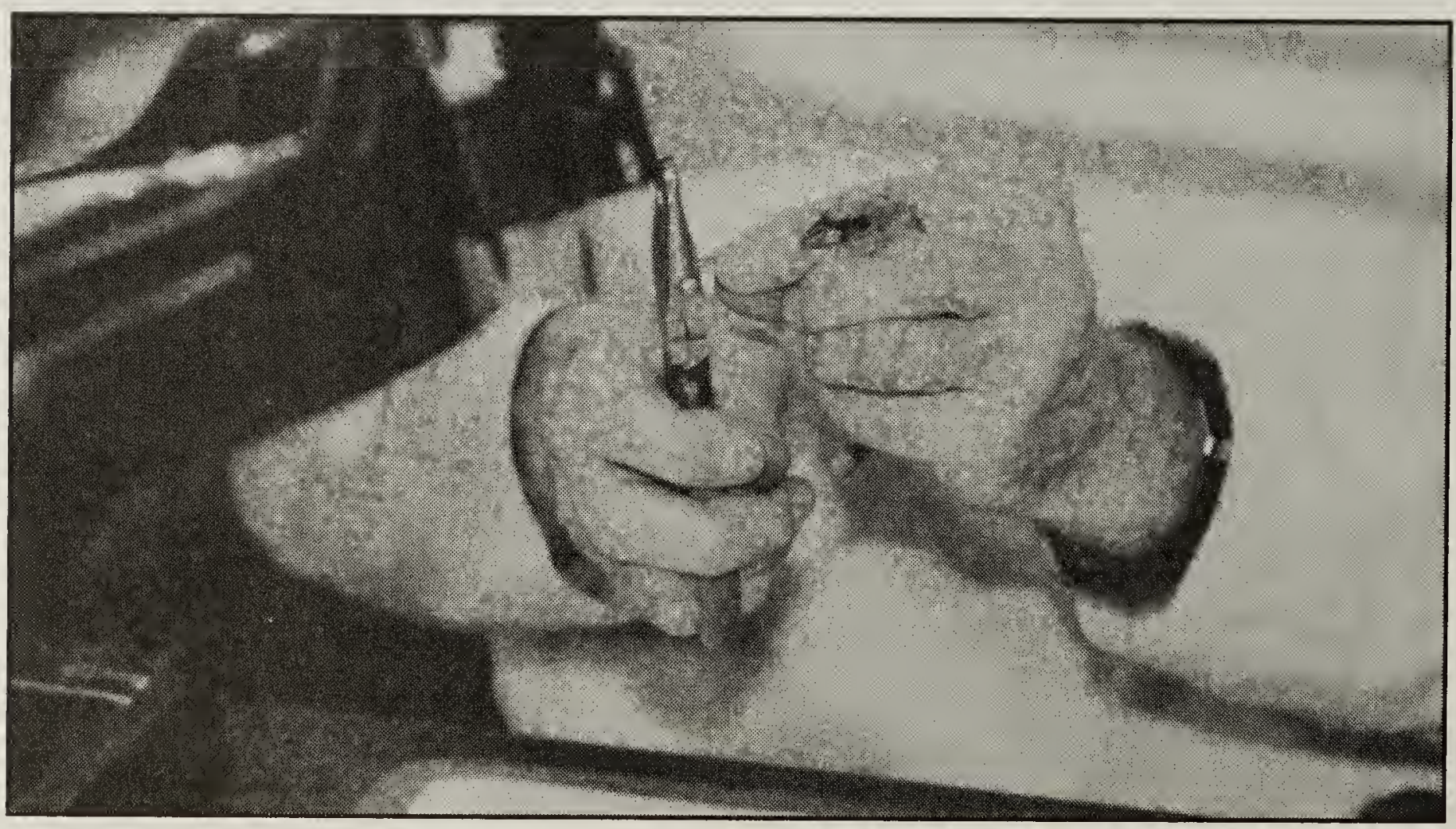


Saskatoon Catholic Schools Foundation, and is mandated to expose students to real-life field study of prairie ecology.

\section{Acknowledgements}

Last Mountain Bird Observatory manager $\mathrm{Al}$ Smith has generously shared his time and expertise. Bird Studies Canada is also to be thanked for assistance with some of the initial start-up costs. Station volunteers include members from the Saskatoon Nature Society, the University of Saskatchewan Extension Division, the Saskatoon Zoo Society, University of Saskatchewan students, as well as staff and students from Saskatoon schools. Special thanks to CWS biologist Brenda Dale for providing additional training opportunities for the volunteers.

1. SMITH, A.R. 1996. Atlas of Saskatchewan Birds. Saskatchewan Natural History Society Special Publication No. 22. Nature Saskatchewan, Regina.

\section{FIRST BREEDING RECORD OF THE DOUBLE-CRESTED CORMORANT IN THE CRESTON VALLEY, BRITISH COLUMBIA}

\section{LINDA M. VAN DAMME, $61920^{\text {th }}$ Avenue; S, Creston, BC V0B 1G5.}

\section{E-mail:1vd2@shaw.ca}



\section{Double-crested Cormorant}

R. Wayne Campbell

\section{Introduction}

The Double-crested Cormorant breeds throughout much of central interior North America, where major concentrations are centered on lakes in the prairie provinces. ${ }^{6,7}$ Smaller numbers breed locally on the Pacific coast and along the Atlantic coast.

In British Columbia, the Double-crested Cormorant breeds regularly in the Strait of Georgia, where it is present year-round. ${ }^{2}$ In the interior, breeding was first confirmed in 1993 when four pairs were found nesting in an American White Pelican colony at Stum Lake, west of Williams Lake. ${ }^{9}$ The only other interior breeding record dates from 1997 when a pair was observed feeding two young on the Cheslatta River, southeast of Burns Lake in the center of the province (Guy Monty, pers. comm.).

This paper documents the third interior breeding of Double-crested Cormorants in British Columbia and discusses interspecific competition with a long-established Great Blue Heron colony known as the Leach Lake colony. 